\title{
Breastfeeding, bottle feeding and risk of malocclusion in mixed and permanent dentitions: a systematic review
}

\section{Lucas Guimarães ABREU Saul Martins PAIVA Isabela Almeida PORDEUS Carolina Castro MARTINS}

Universidade Federal de Minas Gerais - UFMG, School of Dentistry, Department of Pediatric Dentistry and Orthodontics, Belo Horizonte, MG, Brazil.

Declaration of Interests: The authors certify that they have no commercial or associative interest that represents a conflict of interest in connection with the manuscript.

\section{Corresponding Author:}

Lucas Guimarães Abreu

E-mail: lucasgabreu@bol.com.br

DOI: 10.1590/1807-3107BOR-2016.vol30.0022

Submitted: Jun 11, 2015

Accepted for publication: Oct 14, 2015

Last revision: Nov 24, 2015
Abstract: The aim of the present study was to search for scientific evidence concerning the association between breastfeeding and bottle feeding and risk of malocclusion in mixed and permanent dentitions. An electronic search was performed in eight databases up to February 2015. Additionally, a gray literature search and hand searches of the reference lists of the selected studies were also carried out. There were no restrictions on language or on year of publication. The methodology of the included articles was evaluated using the Newcastle Ottawa scale. Out of the 817 identified citations, six studies fulfilled the eligibility criteria and were included in the systematic review. One study showed that children with mixed and permanent dentitions breastfed for more than 6 months presented greater mean protrusion of mandibular incisors and inclination of maxillary incisors compared with those breastfed for less than 6 months or those who were bottle-fed $(p<0.05)$. One study revealed that breastfeeding and bruxism were associated with Class II [OR $=3.14$ (1.28 - 7.66)] and Class III [OR $=2.78(1.21-6.36)]$ malocclusion in children with permanent dentition, while another study showed that an increase in breastfeeding duration was associated with a lower risk of malocclusion in children with both mixed and permanent dentitions $(p<0.001)$. Three studies did not report any significant association. Risk of bias was high in most selected articles. These findings do not support an association between breastfeeding and bottle feeding and the occurrence of malocclusion in mixed and permanent dentitions.

Keywords: Malocclusion; Breast Feeding; Bottle Feeding; Dentition, Mixed; Dentition, Permanent.

\section{Introduction}

Exclusive breastfeeding for at least six months has been highly recommended for preventing gastrointestinal infections and growth deficits in the first months of life. ${ }^{1,2}$ However, the findings of some studies have confirmed the association between feeding habits and the occurrence of malocclusion in the primary dentition. ${ }^{3,4}$ Indeed, both breastfeeding and bottle feeding have been associated with a greater chance of cross-bite development when preschool children are evaluated. ${ }^{5,6}$ Moreover, a recent systematic review has shown that the scientific evidence that breastfeeding 
could protect against malocclusion in the deciduous dentition could not be confirmed. ${ }^{7}$

Non-nutritive sucking habits have been suggested to be a cause for malocclusion in mixed $^{8}$ and permanent ${ }^{9}$ dentitions. There is also some evidence that bottle feeding, ${ }^{8}$ nail biting, object biting, cheek or lip biting and tooth grinding ${ }^{10}$ during the first years of life may be associated with pacifier use or finger sucking habits in children, which, in turn, can increase the risk of malocclusion. Nevertheless, the association between feeding habits history and malocclusion in mixed and permanent dentitions has been poorly discussed thus far. ${ }^{11}$ In addition, there has been no systematic attempt to review and summarize the existing information on this topic.

Therefore, the aim of the present systematic review was to search for scientific evidence of the association between breastfeeding versus bottle feeding and malocclusion in mixed and permanent dentitions. The PICO elements were as follows: children in the mixed and/or permanent dentition stage (patient), bottle feeding (intervention), breastfeeding (comparison), and malocclusion (outcome).

\section{Methodology}

\section{Protocol and registration}

This systematic review was carried out using the Preferred Reporting Items for Systematic Reviews and Meta-Analysis (PRISMA) checklist as a template. ${ }^{12}$ Neither a protocol nor a systematic review registration was considered.

\section{Eligibility criteria}

The inclusion criteria for this systematic review were epidemiological studies (cross-sectional, case-control, cohort studies and clinical trials) addressing breastfeeding, bottle feeding and mixed feeding (bottle and breastfeeding) and risk of malocclusion in mixed or/and permanent dentitions. Studies on primary dentition conducted with children younger than 7 years; epidemiological studies evaluating outcomes other than malocclusion (dental caries, trauma, temporomandibular disorders); and studies reporting risk factors unrelated to feeding or infancy and the treatment, diagnosis or prevention of malocclusion were excluded. So were literature reviews; letters to the editor; case reports; case series; laboratory studies; studies on food intake; and studies addressing parents'/dentists' knowledge about oral health.

\section{Information sources}

A systematic computerized search was performed up to February 2015 in eight electronic databases: Pubmed (http://www.pubmed.gov), Medline via Ovid (http://gateway.ovid.com), Web of Science (http://www.isiknowledge.com), the Cochrane Library (http://www.cochrane.org/index.htm), Clinical Trials (http://controlled-trial.com), UK National Institute for Health and Care Excellence (http://www.nice.org.uk), US National Institutes of Health (http://www.clinicaltrials.gov) and Lilacs and the Brazilian Library of Dentistry (BBO) through the Virtual Health Library (Bireme, Latin America) (www.bireme.br). There were no restrictions on language or on year of publication. The reference lists of the selected articles were also hand-searched for applicable studies that might have been missed in the computerized searches. Additionally, a partial gray literature search was conducted with OpenGrey and Google Scholar limiting the search to the first 100 most relevant hits. The Reference Manager Software ${ }^{\circledR}$ (Reference Manager, Thomson Reuters, version 12.0.3) was used to organize the list of studies. Duplicate results were removed upon identification.

\section{Search strategy}

The following strategy was used in Medline, Pubmed, Web of Science and Cochrane databases: ((malocclusion* OR malocclusion[Mesh] OR dental occlusion[Mesh] OR Maxillofacial Development[Mesh]) AND (bottlefeed* OR bottle feed* OR bottle-feed* OR bottlefed OR bottle fed OR bottle-fed OR "bottle feeding"[Mesh] OR "breast feeding"[Mesh] OR breastfeed* OR breast feed* OR breast-feed* OR breastfed OR breast fed OR breast-fed OR weaning OR "Sucking behavior"[Mesh] OR "Feeding Behavior"[Mesh] OR "risk factors"[Mesh])) NOT ("animals"[Mesh] NOT "humans"[Mesh]). Medline and Pubmed were limited by "humans." Bireme, Clinical Trials, UK National Institute for Health and Care Excellence and US National Institutes of 
Health were searched using combined keywords: "bottle feeding", "breast feeding", "sucking behavior", "weaning" and "malocclusion."

\section{Study selection}

The review process was carried out in two phases. In phase 1, two researchers (CCM and LGA) independently reviewed the list of titles and abstracts for inclusion. Once potentially adequate abstracts were selected, full articles were retrieved for a second selection process. If the abstract was judged to contain insufficient information for a decision of inclusion or exclusion, the full text was obtained and reviewed before a final decision was made. In phase 2, the eligibility criteria were applied to the full articles by the same two researchers (CCM and LGA). In both phases, any discrepancies in the inclusion of the articles between researchers were addressed through discussion until consensus was reached.

\section{Data collection process}

Two researchers (CCM and LGA) independently extracted data from the articles that met the inclusion criteria and compared their findings for accuracy. They discussed and re-examined any discrepancies until an agreement was reached. When additional or missing information was required, the authors of the articles were contacted.

\section{Data items}

Data on the following items were collected: country, study design, initial and final sample, data collection setting, child's age at the time of the dental examination, how data on feeding habits were collected, how malocclusion was evaluated, statistical analyses, adjustment for confounders, overall result and direction of the effect (statistically significant or not).

The main outcome was malocclusion, which was considered the endpoint of disease (present/absent). Feeding habits were extracted as categorical or numerical variables based on the duration of breastfeeding and bottle feeding, as reported by the authors. Confounders and interactions were extracted and described when evaluated in the multivariate analyses.

\section{Risk of bias in individual studies}

The methodological quality was assessed by two researchers (CCM and LGA) using the Newcastle-Ottawa scale for case-control studies and the modified Newcastle-Ottawa scale for cross-sectional ones. ${ }^{13}$ For the case-control studies, a quality score was calculated based on three major categories: group selection (four items), comparability between groups (one item), and outcome and exposure assessment (three items). A maximum of one point was allocated to each item in the group selection and outcome and exposure assessment categories and a maximum of two points was awarded for comparability. Therefore, the maximum score was nine points and represented the highest methodological quality. For the cross-sectional studies, the score was calculated based on the same three categories. However, those categories had a different number of items: group selection (two items), comparability (one item), and outcome and exposure assessment (two items). Thus, the maximum score was six points and also indicated the highest methodological quality. Any disagreement between researchers was resolved by means of discussion.

\section{Summary measures}

Any outcome measure that evaluated the association between breastfeeding and bottle feeding and malocclusion in mixed and permanent dentitions was considered and included odds ratio (OR) and confidence intervals $(\mathrm{CI})$. For the studies in which $\mathrm{CI}$ were not provided, $\mathrm{p}$-values were presented.

\section{Synthesis of the results and risk of bias across studies}

The heterogeneity among the included studies was evaluated through the examination of various characteristics of the finally selected reports, such as dissimilarity between study participants and outcomes. ${ }^{14}$ If the data were homogeneous and appropriate for pooling, then a meta-analysis would be considered. If the data were heterogeneous and inappropriate for a meta-analysis, a qualitative synthesis would be performed instead. 


\section{Additional analysis}

Publication bias was considered as an additional analysis.

\section{Results}

\section{Study selection}

The computerized search yielded 958 references across the eight electronic databases. After removal of duplicate references, 817 titles and abstracts were read and analyzed in phase 1, of which 615 were excluded. Therefore, a total of 202 studies were selected for the analysis of the full texts in phase 2. After reading of the full texts, only six articles ${ }^{15,16,17,18,19,20}$ met the eligibility criteria and were included in the present systematic review. A list of the articles excluded in phase 2 along with the reasons for their exclusion is displayed in Appendix 1 and is available upon request. One report was identified through the hand-search of the reference lists. No article was identified through the gray literature search. A flowchart depicting the selection process of the articles at each stage of the systematic review is provided in Figure.

\section{Study characteristics}

Among the six articles included in the present systematic review, one was a case-control ${ }^{16}$ study and five were cross-sectional studies. ${ }^{15,17,18,19,20}$ Table 1 provides a summary of their characteristics, including methodological data and relevant findings.

All articles were published in English. One study was a population-based study with data collected from the US National Health Interview Survey (NHIS), representing the American population aged 9 to 17 years. ${ }^{15}$ One study provided sample size calculation and was representative of a Brazilian city. ${ }^{20}$ The other four papers involved convenience samples. ${ }^{16,17,18,19}$ One included participants from a private office, ${ }^{16}$ one included individuals from a university setting, ${ }^{19}$ one included adolescents from schools of an Italian city, ${ }^{18}$ and one included individuals from three public schools of a Brazilian city. ${ }^{17}$

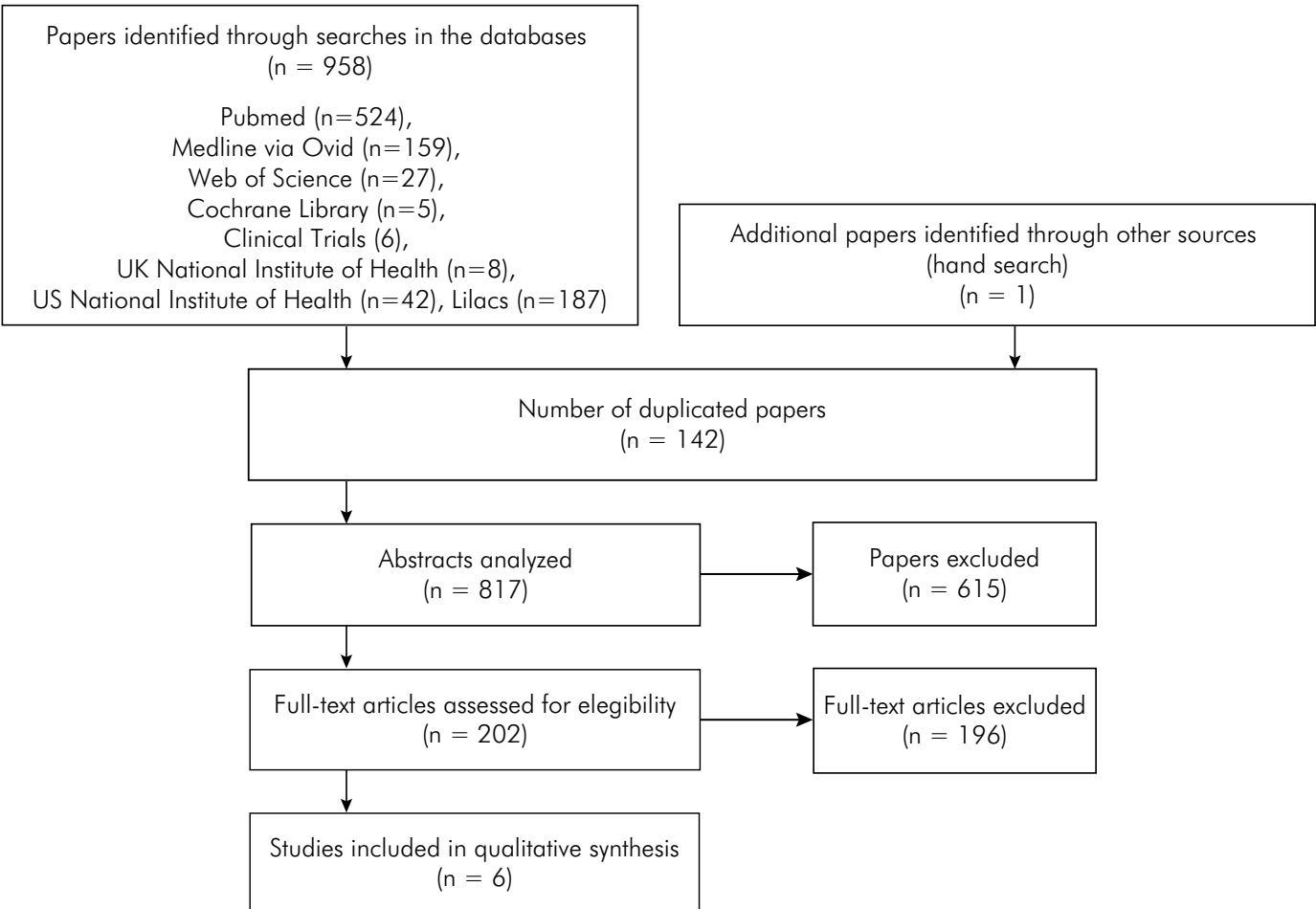

Figure. Flowchart showing the results of the search process. 

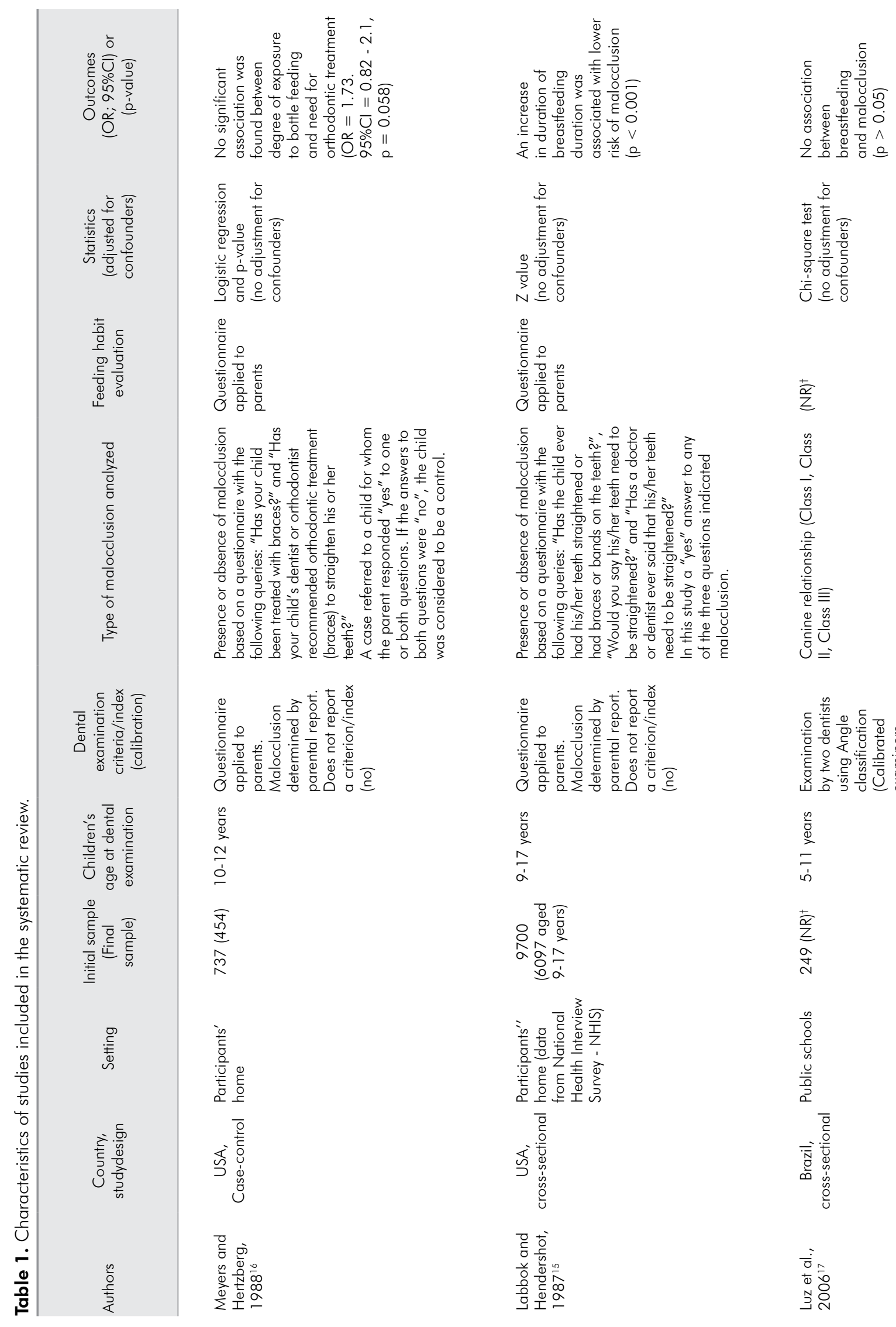

$\stackrel{t}{\underline{s}}$
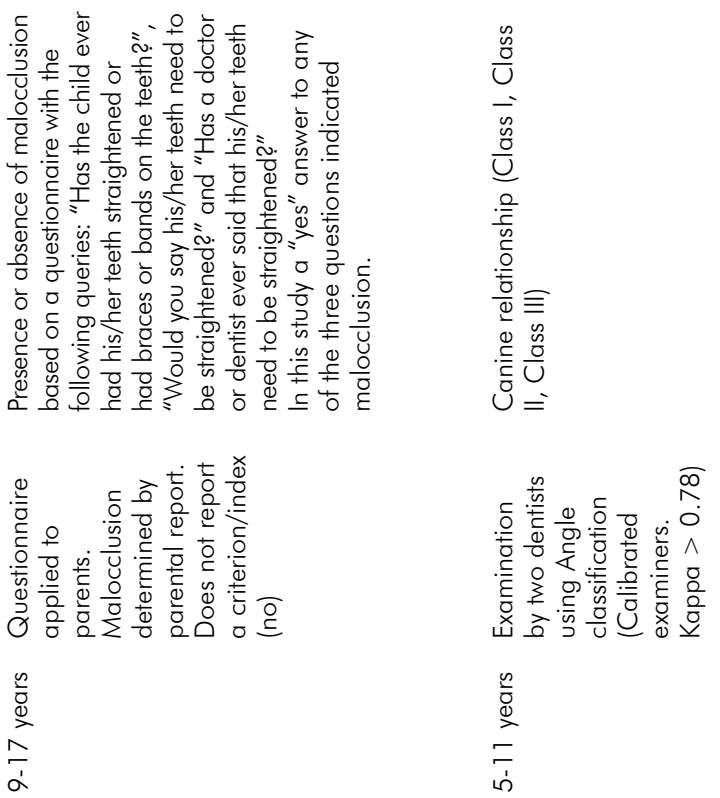

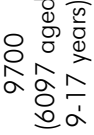

$\frac{+}{a}$
a
d

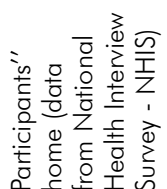

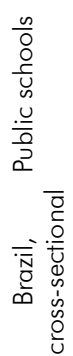

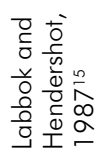

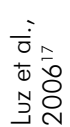




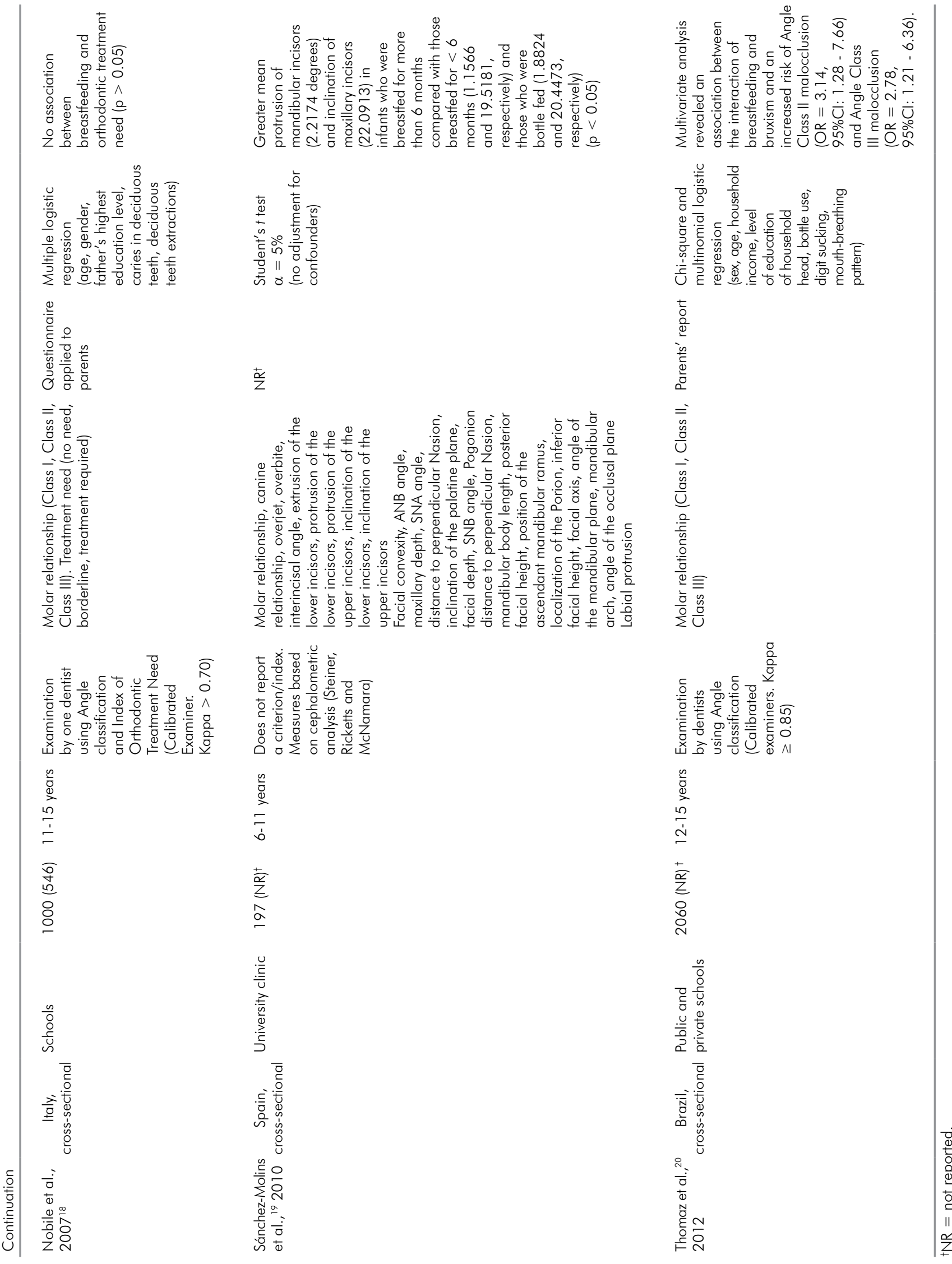


Two studies revealed the existence of malocclusion through parents' reports, ${ }^{15,16}$ in which parents were asked if a dentist had ever said that their children needed braces or if the parents had perceived that their children needed braces or orthodontic treatment. In three studies, the diagnosis of malocclusion was established in a clinical evaluation performed by calibrated dentists. ${ }^{1718,20}$ In another study, malocclusion was evaluated based on cephalometric data. ${ }^{19} \mathrm{In}$ four studies, ${ }^{15,16,18,20}$ feeding habits were determined from a questionnaire administered to parents and two studies ${ }^{17,19}$ failed to report how data on feeding habits were collected.

In general, the studies lacked details, in the Methods section, of approval by the institutional ethics committee. ${ }^{15,16,17,18,19}$ Nonetheless, all papers had sufficient information for data collection for the systematic review. ${ }^{15,16,17,18,19,20}$

\section{Risk of bias in individual studies}

The methodological quality evaluation using the Newcastle-Ottawa scale is shown in Tables 2 and 3. The case-control study ${ }^{16}$ scored three points (Table 2). The scores for the cross-sectional studies $15,17,18,19,20$ ranged from one to four points (Table 3).

\section{Results of individual studies}

One study showed no significant association between the duration of bottle feeding and the need for orthodontic treatment $[\mathrm{OR}=1.73$ $(\mathrm{CI}=0.82-2.10), \mathrm{p}=0.058)]{ }^{16}$ Another study reported that a longer breastfeeding period was associated with a decreased risk of malocclusion $(\mathrm{p}<0.001)^{15}$ Only one study adjusted the statistical analysis for confounders and found an interaction between the history of breastfeeding and bruxism, with a synergistic effect on significantly increasing the risk of Angle Class II [OR $=3.14(\mathrm{CI}=1.28-7.66)$, $\mathrm{p}<0.05)]$ and Class III malocclusion [OR $=2.78$ $(\mathrm{CI}=1.21$ - 6.36), $\mathrm{p}<0.05)] \cdot{ }^{20}$ Based on cephalometric data, children breastfed for more than 6 months had greater mean protrusion of mandibular incisors $(p=0.023)$ and inclination of maxillary incisors $(p=0.047)$ in comparison with children who were breastfed for 6 months or less. Children breastfed for more than 6 months also presented a greater mean protrusion of mandibular incisors and inclination of maxillary incisors when compared with bottle-fed children $(\mathrm{p}<0.05) .{ }^{19}$ Two studies did not report any significant association $(p>0.05) .{ }^{17,18}$

\section{Synthesis of the results and risk of bias across studies}

A meta-analysis was not possible. The six studies included in this systematic review described different types of malocclusion and used different cut-off times to evaluate feeding practices. Therefore, the pooled data from those studies were deemed not suitable because of the differences in the study designs and in the collected information.

\section{Additional analysis}

Publication bias was not assessed as there were not enough studies to be entered into a funnel plot.

\section{Discussion}

This systematic review attempted to evaluate the association between feeding habits and malocclusion in mixed and permanent dentitions. Oral and craniofacial development may be a health issue on which feeding practices may have a measurable and relevant impact. ${ }^{21}$ Although the first study addressing this topic in schoolchildren and adolescents dates back to more than 25 years, the question remains unanswered and conclusions are yet to be fully confirmed.

One study showed an association between breastfeeding duration and an increased risk of malocclusion, ${ }^{15}$ while another one did not reveal any statistical significance between feeding habits and malocclusion. ${ }^{16}$ However, those studies lacked a clinical evaluation of malocclusion, which was determined through parents' reports. The clinical data collected from parents' reports may be subjective and prone to information bias and, therefore, unreliable. ${ }^{22}$

One study revealed an interaction between breastfeeding and bruxism, which increased the risk of Class II and Class III malocclusion. This study conducted a multinomial regression analysis, considering gender, age, household income, education level, bottle use, bruxism, digit sucking habit and mouth breathing pattern as confounding variables. ${ }^{20}$ 


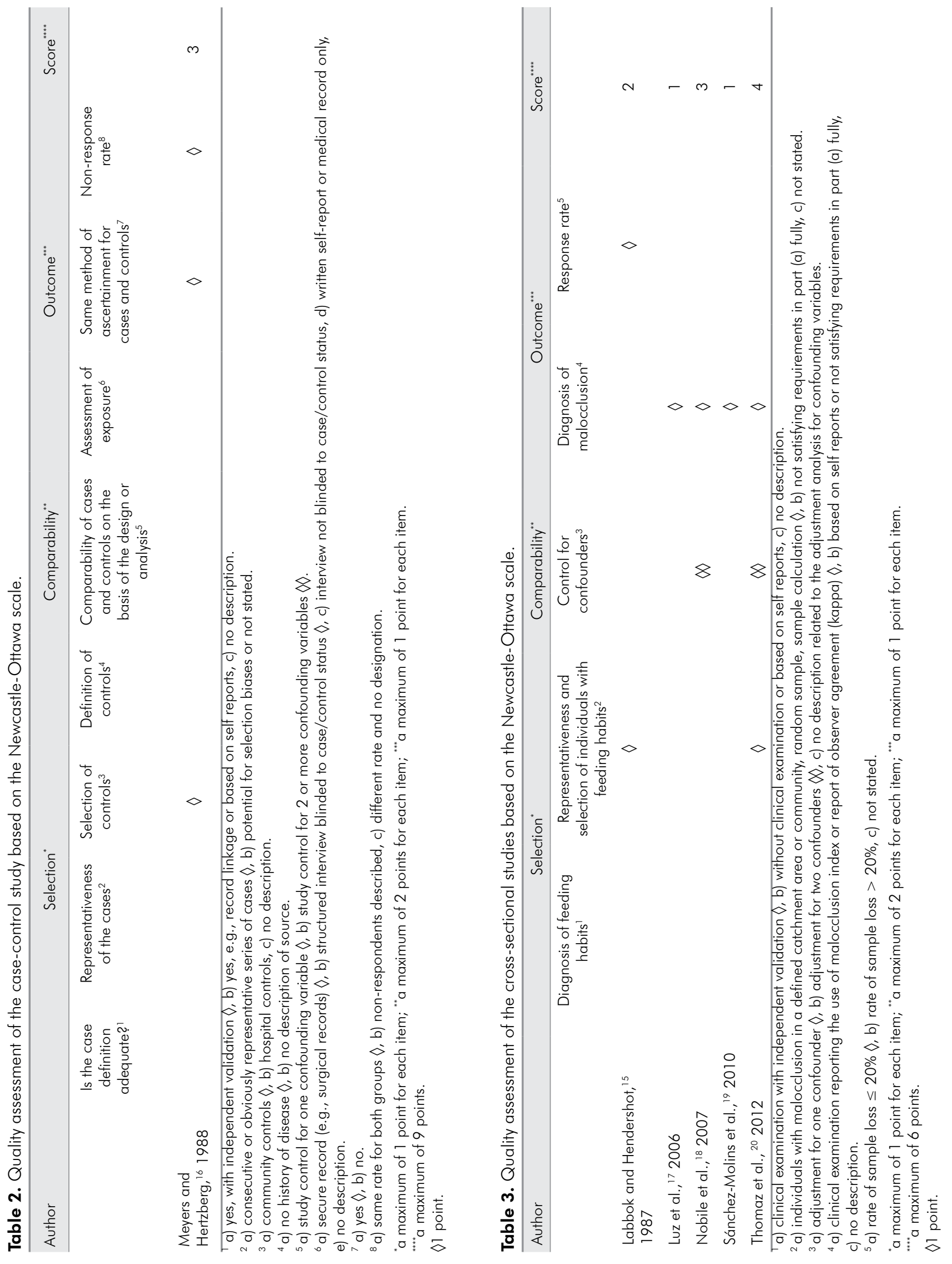


Adjustment for confounders is very important in epidemiological studies, since an outcome, such as malocclusion, may be associated with multiple risk factors, including gender, genetics, income, feeding practice, non-nutritive sucking habit and other harmful oral habits. ${ }^{23}$ Failure to evaluate demographic and clinical factors as potential confounders can bias study results and lead to erroneous conclusions. ${ }^{24}$ Also, the methodology of this study was strengthened by the adoption of a representative sample of Brazilian adolescents, allowing the authors to perform a meaningful statistical analysis and to generalize the results for that population. ${ }^{25}$

When malocclusion was determined based on cephalometric data, greater mean protrusion of the mandibular incisors and inclination of the maxillary incisors seem to occur among children breastfed for more than 6 months in comparison with those breastfed for less than 6 months and those who were bottle-fed.$^{19}$ Notwithstanding, this study presented the lowest methodology quality and shortcomings with respect to response rate, sample representativeness, control for confounding variables, and selection of individuals with feeding habits.

Some limitations of the present systematic review should be acknowledged. The first one regards the lack of homogeneous data for a meta-analysis. The included studies had different methodologies and different measures for malocclusion, thus hindering the pooling of data. ${ }^{14}$ The second flaw noted during data compilation was the limited number of articles that met our eligibility criteria. Additionally, most evidence found was cross-sectional and no high quality study addressing the association between feeding habits and the occurrence of malocclusion in mixed and permanent dentitions was identified.
Finally, the authors of the included articles were unable to group, separately, children who had exclusive breastfeeding or bottle feeding and mixed feeding, making the comparison between those groups impossible. Therefore, breastfeeding and bottle feeding could not be confirmed as risk factors for malocclusion in children and adolescents.

Further research with stronger methodological strategies should be conducted to examine the association between feeding habits and malocclusion in mixed and permanent dentitions. Future studies should also consider the longitudinal design to assess such association more accurately. In cohort evaluations, participants are disease-free at the onset of the study and data regarding exposure to risk factors are collected at distinct points in time before the outcome. Thus, this design enables the assessment of causal hypothesis. ${ }^{26}$

\section{Conclusion}

The findings presented herein do not support an association between breastfeeding and bottle feeding and the occurrence of malocclusion in mixed and permanent dentitions.

The association between feeding practices and this outcome of concern requires additional investigation through prospective cohort studies.

\section{Acknowledgments}

This study was supported by the Coordenação de Aperfeiçoamento do Pessoal de Nivel Superior - CAPES, Fundação de Amparo à Pesquisa do estado de Minas Gerais - FAPEMIG, Conselho Nacional de Desenvolvimento Científico e Tecnológico - CNPq, and Pró-Reitoria de Pesquisa/Universidade Federal de Minas Gerais - PRPq/UFMG. 


\section{References}

1. Kramer MS, Kakuma R. Optimal duration of exclusive breastfeeding. Cochrane Database Syst Rev. 2012 Aug15;8:CD003517. doi:10.1002/14651858.CD003517.pub2

2. World Heatlh Organization. Exclusive breastfeeding for six months best for babies everywhere. 2011. [cited 2013 Jan 27]. Geneva: HOW; 2011. Available from: http:// www.who.int/mediacentre/news/statements/2011/ breastfeeding_20110115/en/

3. Vázquez-Nava F, Quezada-Castillo JA, Oviedo-Trevino S, Saldivar-González AH, Sánchez-Nuncio HR, BeltránGuzmán FJ, et al. Association between allergic rhinitis, bottle feeding, non-nutritive sucking habits, and malocclusion in the primary dentition. Arch Dis Child. 2006;91(10):836-40. doi:10.1136/adc.2005.088484

4. Peres KG, Barros AJ, Peres MA, Victora CG. Effects of breastfeeding and sucking habits on malocclusion in a birth cohort study. Rev Saude Publica. 2007;41(3):343-50. doi:10.1590/1 S0034-89102007000300004

5. Karjalainen S, Ronning O, Lapinleimu H, Simell O. Association between early weaning, non-nutritive sucking habits and occlusal anomalies in 3-year-old Finnish children. Int J Paediatr Dent. 1999;9(3):169-73. doi:10.1046/j.1365-263x.1999.00133.x

6. Viggiano D, Fasano D, Monaco G, Strohmenger L. Breast feeding, bottle feeding, and non-nutritive sucking; effects on occlusion in deciduous dentition. Arch Dis Child. 2004;89(12):1121-3. doi:10.1136/adc.2003.029728

7. Hermont AP, Martins CC, Zina LG, Auad SM, Paiva SM, Pordeus IA. Breastfeeding, bottle feeding practices and malocclusion in the primary dentition: a systematic review of cohort studies. Int J Environ Res Public Health. 2015;12(3):3133-51. doi:10.3390/ijerph120303133

8. Montaldo L, Montaldo P, Cuccaro P, Caramico N, Minervini G. Effects of feeding on non-nutritive sucking habits and implications on occlusion in mixed dentition. Int J Paediatr Dent. 2011;21(1):68-73. doi:10.1111/j.1365-263X.2010.01092.x

9. Mistry P, Moles DR, O'Neill J, Noar J. The occlusal effects of digit sucking habits amongst school children in Northamptonshire (UK). J Orthod. 2010;37(2):87-92. doi:10.1179/14653121042939

10. Thomaz EBAF, Cangussu MCT, Assis AMO. Malocclusion and deleterious oral habits among adolescents in a developing area in northeastern Brazil. Braz Oral Res 2013;27(1):62-9. doi:10.1590/S1806-83242012005000027

11. Narbutyte I, Narbutyte A, Linkeviciene L. Relationship between breastfeeding, bottle-feeding and development of malocclusion. Stomatologija. 2013;15(3):67-72.

12. Moher D, Liberati A, Tetzlaff J, Altman DG, PRISMA Group. Preferred reporting items for systematic reviews and meta-analysis: the PRISMA statement. J Clin Epidemiol. 2009;62(10):1006-12. doi:10.1016/j.jclinepi.2009.06.005
13. Wells GA, Shea B, O'Connell D, Peterson J, Welch V, Losos $\mathrm{M}$, et al. The Newcastle-Ottawa Scale (NOS) for assessing the quality of nonrandomized studies in meta-analyses [Internet]; Ottawa: Ottawa Hospital Research Institute; 2009 [cited 2013 Dec 15]. Available from: www.ohri.ca/programs/ clinical_epidemiology/oxford.htm

14. Higgins JP, Thompson SG. Quantifying heterogneneity in meta-analysis. Stat Med. 2002 Jun;21(11):1539-58. doi:10.1002/sim.1186

15. Labbok MH, Hendershot GE. Does breast-feeding protect against malocclusion? An analysis of the 1981 Child Health Supplement to the National Health Interview Survey. Am JPrev Med. 1987;3(4):227-32. doi:10.1016/j.earlhumdev.2007.12.008

16. Meyers A, Hertzberg J. Bottle-feeding and malocclusion: is there an association? Am J Orthod Dentofacial Orthop. 1988;93(2):149-52. doi:10.1016/0889-5406(88)90293-4

17. Luz CL, Garib DG, Arouca R. Association between breastfeeding duration and mandibular retrusion: a cross-sectional study of children in the mixed dentition. Am J Orthod Dentofacial Orthop. 2006;130(4):531-4. doi:10.1016/j.ajodo.2006.06.011

18. Nobile CG, Pavia M, Fortunato L, Angelillo IF. Prevalence and factors related to malocclusion and orthodontic treatment need in children and adolescents in Italy. Eur J Public Health. 2007;17(6):637-41.

19. Sánchez-Molins M, Grau Carbó J, Lischeid Graig C, Ustrell Torrent JM. Comparative study of the craniofacial growth depending on the type of lactation received. Eur J Paediatr Dent. 2010;11(2):87-92.

20. Thomaz EB, Cangussu MC, Assis AM. Maternal breastfeeding, parafunctional oral habits and malocclusion in adolescents: a multivariate analysis. Int J Pediatr Otorhinolaryngol. 2012;76(4):500-6. doi:10.1016/j.ijporl.2012.01.005

21. Davis DW, Bell PA. Infant feeding practices and occlusal outcomes: a longitudinal study. J Can Dent Assoc. 1991;57(7):593-4.

22. Choi BCK, Pak AWP. A catalog of biases in questionnaires. Prev Chronic Dis [Internet]. 2005 Jan [cited 2008 Mar 13]:2(1) A13. Available from: www.cdc.gov/pcd/issues/2005/ jan/04_0050.htm

23. McKeever A. Genetics versus environment in the aetiology of malocclusion. Br Dent J. 2012;212(11):527-28. doi:10.1038/sj.bdj.2012.465

24. Skelly AC, Dettori JR, Brodt ED. Assessing bias: the importance of considering confounding. Evid Based Spine Care J. 2012;3(1):9-12. doi:10.1055/s-0031-1298595

25. Suresh K, Chandrashekara S. Sample size estimation and Power analysis for clinical research studies. J Hum Reprod Sci. 2012;5(1):7-13. doi:10.4103/0974-1208.97779

26. Levin KA. Study design IV. Cohort studies. Evid Based Dent. 2006;7(2):51-2. doi:10.1038/sj.ebd.6400407 


\section{Appendix 1: Articles excluded after full text evaluation and reasons for exclusion}

\section{Reference}

1. Backlund E. Facial growth, and the significance of oral habits, mouthbreathing and soft tissues for malocclusion. A study on children around the age of 10. Acta Odontol Scand 1963; 21:9-139.

2. Paunio P, Rautava P, Sillanpaa M. The Finnish Family Competence Study: the effects of living conditions on sucking habits in 3-year-old Finnish children and the association between these habits and dental occlusion. Acta Odontol Scand 1993; 51 (1):23-29.

3. Carrero dH, Valls dW, Arenas dG. [Functions of the stomatognathic system and occlusopathics]. Acta Odontol Venez 1988; 26(3):41-47.

4. Saenz RB, Sánchez O. Breast-feeding and infant oral health. Am Fam Physician 2000; 62(3):506-507.

5. Baume LJ. Uniform methods for the epidemiologic assessment of malocclusion. Results obtained with the World Health Organization standard methods (1962 and 1971) in South Pacific populations. Am J Orthod 1974; 66(3):251-272.

6. Larsson EF, Dahlin KG. The prevalence and the etiology of the initial dummy- and finger-sucking habit. Am J Orthod 1985; 87(5):432-435.

7. Hannuksela A, Vaananen A. Predisposing factors for malocclusion in 7-year-old children with special reference to atopic diseases. Am J Orthod Dentofacial Orthop 1987; 92(4):299-303.

8. Ogaard B, Larsson E, Lindsten R. The effect of sucking habits, cohort, sex, intercanine arch widths, and breast or bottle feeding on posterior crossbite in Norwegian and Swedish 3-year-old children. Am J Orthod Dentofacial Orthop 1994; 106(2):161-166.

9. Warren JJ, Bishara SE. Duration of nutritive and nonnutritive sucking behaviors and their effects on the dental arches in the primary dentition. Am J Orthod Dentofacial Orthop 2002; 121 (4):347-356.

10. Katz CR, Rosenblatt A, Gondim PP. Nonnutritive sucking habits in Brazilian children: effects on deciduous dentition and relationship with facial morphology. Am J Orthod Dentofacial Orthop 2004; 126(1):53-57.

11. Cozza P, Baccetti T, Franchi L, Mucedero M, Polimeni A. Sucking habits and facial hyperdivergency as risk factors for anterior open bite in the mixed dentition. Am J Orthod Dentofacial Orthop 2005; 128(4):517-519.

12. Frazao P, Narvai PC. Socio-environmental factors associated with dental occlusion in adolescents. Am J Orthod Dentofacial Orthop 2006; 129(6):809-816.

13. Bishara SE, Warren JJ, Broffitt B, Levy SM. Changes in the prevalence of nonnutritive sucking patterns in the first 8 years of life. Am J Orthod Dentofacial Orthop 2006; 130(1):31-36.

14. Ovsenik M. Incorrect orofacial functions until 5 years of age and their association with posterior crossbite. Am J Orthod Dentofacial Orthop 2009; 136(3):375-381.

15. Kobayashi HM, Scavone H, Jr., Ferreira RI, Garib DG. Relationship between breastfeeding duration and prevalence of posterior crossbite in the deciduous dentition. Am J Orthod Dentofacial Orthop 2010; 137(1):54-58.

16. Larsson E. Sucking, chewing, and feeding habits and the development of crossbite: a longitudinal study of girls from birth to 3 years of age. Angle Orthod 2001; 71 (2):116-119.

\section{Classification}

Not selected - The study reports breathing.

Not selected - Breast feeding and bottle feeding are not associated to malocclusion, are only associated to sucking habits.

Not selected - Review

Not selected - Letters to the Editor

Not selected - Study describes the prevalence of malocclusion and dental eruption pattern in Polynesian population. Risk factors are not reported.

Not selected - The study describes prevalence of sucking habits, and does not report association of breat feeding or bottle feeding with malocclusion.

Not selected - The study does not report breast feeding or bottle feeding, only associates malocclusion to other risk factors.

Not selected - Data could not be extracted for meta-analysis.

Not selected - the study is conducted with children under primary dentition

Not selected - The study does not report breast feeding or bottle feeding, but other risk factors.

Not selected - The study does not report breast feeding or bottle feeding.

Not selected - The study analyses epidemiological survey of the Brazilian Health Authority. No risk factors are reported.

Selected- The study is from lowa Fluoride Study. However did not enter meta-analysis.

Not selected - breast feeding is not reported. Bottle feeding is reported along years, and there is no frequency data or OR that could be extracted.

Not selected - the study is conducted with children under primary dentition

Not selected - The study does not associates breast feeding or bottle feeding to malocclusion. Breast feeding is only associated to sucking habits. 
17. Antonini A, Marinelli A, Baroni G, Franchi L, Defraia E. Class II malocclusion with maxillary protrusion from the deciduous through the mixed dentition: a longitudinal study. Angle Orthod 2005; 75(6):980-986.

18. Gois EG, Ribeiro-Junior HC, Vale MP, Paiva SM, Serra-Negra $J M$, Ramos-Jorge ML et al. Influence of nonnutritive sucking habits, breathing pattern and adenoid size on the development of malocclusion. Angle Orthod 2008; 78(4):647-654.

19. Aznar T, Galan AF, Marin I, Dominguez A. Dental arch diameters and relationships to oral habits 15. Angle Orthodontist 2006; 76(3):441-445.

20. Popovich $F$. The prevalence of sucking habit and its relationship to oral malformations. Appl Ther 1966; 8(8):689-691.

21. Eskes PW. Aetiology of malocclusion of the teeth. Arch Dis Child 1992; 67(3):352.

22. Winter GB. Problems involved with the use of comforters. Arch Dis Child 2002; 87(2): 170.

23. Viggiano D, Fasano D, Monaco G, Strohmenger L. Breast feeding, bottle feeding, and non-nutritive sucking; effects on occlusion in deciduous dentition. Arch Dis Child 2004; 89(12):1121-1123.

24. Vazquez-Nava F, Quezada-Castillo JA, Oviedo-Trevino S, Saldivar-Gonzalez AH, Sanchez-Nuncio HR, Beltran-Guzman FJ et al. Association between allergic rhinitis, bottle feeding, non-nutritive sucking habits, and malocclusion in the primary dentition. Arch Dis Child 2006; $91(10): 836-840$.

25. Courson F. [Dental facial orthopedics in young children] Arch Pediatr 2006; 13(6):679-682.

26. Ferro A, Cefariello S. [Prevention of malocclusion]. Arch Stomatol (Napoli) 1979; 20(3):387-410.

27. Legovic M, Ostric L. The effects of feeding methods on the growth of the jaws in infants. ASDC J Dent Child 1991; 58(3):253-255.

28. Turgeon-O'Brien H, Lachapelle D, Gagnon PF, Larocque I, Maheu-Robert LF. Nutritive and nonnutritive sucking habits: a review. ASDC J Dent Child 1996; 63(5):321-327.

29. Bowden BD. The effects of digital and dummy sucking on arch widths, overbite, and overiet: a longitudinal study. Aust Dent J 1966; $11(6): 396-404$.

30. Homan BT, Davies GN. An oral health survey of Aborigines and Torres Strait Islanders in far North Queensland. Aust Dent J 1973; 18(2):75-87.

31. Solano RE, Martin de Agar Valverde MC, Mendoza MA. [Study of etiopathogenic factors in Class II malocclusion]. Av Odontoestomatol 1988; 4(2):69-79.

32. Kieser JJ. Occlusal misconceptions. Br Dent J 2002; 192(4):183.

33. Scavone H, Jr., Ferreira RI, Mendes TE, Ferreira FV. Prevalence of posterior crossbite among pacifier users: a study in the deciduous dentition. Braz Oral Res 2007; 21 (2):153-158.

34. Gariner D. Abnormal muscle function and the dentition. Bull N J Soc Dent Child 1970; 17(3):6-10.

35. Emmerich A, Fonseca L, Elias AM, de Medeiros UV.

[The relationship between oral habits, oronasopharyngeal alterations, and malocclusion in preschool children in Vitoria, Espirito Santo, Brazil]. Cad Saude Publica 2004; 20(3):689-697.

36. Bertrand FR. The relationship of prolonged breast feeding to facial features. Cent Afr J Med 1968; 14(10):226-227.

37. Kisling E, Krebs G. Patterns of occlusion in 3-year-old Danish children. Community Dent Oral Epidemiol 1976; 4(4):152-159.
Not selected - The study associates malocclusion to skeletal characteristics based on cephalograms. No breast feeding or bottle feeding is reported.

Not selected - The study does not report breast feeding or bottle feeding. It associates malocclusion to other risk factors.

Not selected - Data could not be extracted for meta-analysis.

Not selected - The study does not associates malocclusion to bottle or breast feeding.

Not selected - Letter to the Editor

Not selected - Letter to the Editor

Not selected - the study is conducted with children under primary dentition

Not selected - the study is conducted with children under primary dentition

Not selected - Review

Not selected - The study does not associates malocclusion to bottle or breast feeding.

Not selected - the study is conducted with children under primary dentition

Not selected - Review

Not selected -The study does not report breast feeding or bottle feeding; only non-nutritive sucking habits.

Not Selected - The study is a survey of oral disease in Aborigines population. No risk factors are reported.

Not selected - The study does not associates malocclusion to bottle or breast feeding.

Not selected - Letter to the Editor

Not selected - The study does not report breast feeding or bottle feeding; only non-nutritive sucking habits.

Not selecte - The study is a review.

Not selected - The study does not report breast feeding or bottle feeding; only non-nutritive sucking habits and oronasopharyngeal alterations.

Not selected - The study does not report epidemiological and quantitative data on breast feeding.

Not selected - The study is a survey of patterns of occlusion in 3 year-old children. Oral habits are seldom reported as non-nutritive sucking habits associated to malocclusion. 
38. Scavone H, Guimaraes CH, Ferreira Rl, Nahas ACR, Vellini-Ferreira F. Association between breastfeeding duration and non-nutritive sucking habits 7. Community Dental Health 2008; 25(3):161-165.

39. Adamiak E. [Prevalence of occlusal disorders in preschool children in rural areas in relation to various individual factors]. Czas Stomatol 1981; 34(5):551-555.

40. Baragona PM, Cohen HV. Long-term orthopedic appliance therapy. Dent Clin North Am 1991; 35(1):109-121.

41. Sanger RG, Bystrom EB. Breast feeding: does it affect oral facial growth? Dent Hyg (Chic) 1982; 56(6):44-47.

42. Simpson WJ, Cheung DK. Developing infant occlusion, related feeding methods and oral habits. Part I: methodology and results at 4 and 8 months. Dent J 1976; 42(3):124-132.

43. Simpson WJ, Cheung DK. Developing infant occlusion, related feeding methods and oral habits. Part II: discussion and conclusions. Dent J 1976; 42(3): 135-7,142.

44. Leighton BC. Symposium on aspects of the dental development of the child. 2. The early development of cross-bites. Dent Pract Dent Rec 1966; 17(4): 145-152.

45. Moss JP, Picton DC. The problems of dental development among the children on a Greek island. Dent Pract Dent Rec 1968; 18(12):442-448.

46. Castillo B. [Pacifier use in early infancy in relation to breast feeding, sudden infant death syndrome and poor dental occlusion]. Enferm Clin 2008; 18(4):223-225.

47. Melsen B, Stensgaard K, Pedersen J. Sucking habits and their influence on swallowing pattern and prevalence of malocclusion. Eur J Orthod 1979; 1 (4):271-280.

48. Larsson E. The effect of dummy-sucking on the occlusion: a review. Eur J Orthod 1986; 8(2):127-130.

49. Tschill P, Bacon W, Sonko A. Malocclusion in the deciduous dentition of Caucasian children. Eur J Orthod 1997; 19(4):361-367.

50. Ovsenik M, Farcnik FM, Korpar M, Verdenik I. Follow-up study of functional and morphological malocclusion trait changes from 3 to 12 years of age. Eur J Orthod 2007; 29(5):523-529.

51. Michelotti A, Farella M, Buonocore G, Pellegrino G, Piergentili C, Martina R. Is unilateral posterior crossbite associated with leg length inequality? Eur J Orthod 2007; 29(6):622-626.

52. Heimer MV, Tornisiello Katz CR, Rosenblatt A. Non-nutritive sucking habits, dental malocclusions, and facial morphology in Brazilian children: a longitudinal study. Eur J Orthod 2008; 30(6):580-585

53. Macena MC, Katz CR, Rosenblatt A. Prevalence of a posterior crossbite and sucking habits in Brazilian children aged 18-59 months. Eur J Orthod 2009; 31 (4):357-361.

54. Peres KG, Barros AJD, Victora CG, Peres MA. Breastfeeding and non-nutritive sucking habits effects on malocclusion in primary dentition 13. European Journal of Epidemiology 2006; 21:36.

55. Gyorgy I. [Prevention of occlusion anomalies]. Fogorv Sz 1970; 63(1):24-26.

56. Pal A. [Observations on the dynamics and etiology of vertical anomalies of the dentition]. Fogorv Sz 1976; 69(5):129-133.

57. Bigenzahn W, Fischman L, Mayrhoferkrammel U. Myofunctional Therapy in Patients with Orofacial Dysfunctions Affecting Speech 25. Folia Phoniatrica 1992; 44(5):238-244.
Not selected - The study does not associates breast feeding or bottle feeding to malocclusion; breast feeding is associated to non-nutritive sucking habits.

Not selected - The study does not associates malocclusion to bottle or breast feeding.

Not selected- Review

Not selected - The study is not original paper.

Not selected - there is no statistical data, only frequency is reported. It was not possible to extract data.

Not selected - there is no statistical data, only frequency is reported. It was not possible to extract data.

Not selected - Risk factors are seldom reported as non-nutritive sucking habits. Breast feeding or bottle feeding are not reported.

Not selected - the study described data of breast feeding in children with primary dentition.

Not selected - Review

Not selected- The study does not report breast feeding or bottle feeding; it associates malocclusion to non-nutritive sucking habits and swallowing pattern.

Not selected - Review

Not selected - The study reports prevalence of malocclusion in children; it does not report risk factors.

Not selected - The study longitudinally follows up children to evaluate changes of malocclusion pattern during years. Bottle feeding of children with malocclusion is reported along the years, but there is no information of bottle feeding in children without malocclusion. OR is not reported and it was not possible to obtain this data from the paper.

Not selected - The study associates malocclusion to leg length inequality in adolescents; no breast feeding or bottle feeding is reported.

Not selected - The study associates malocclusion to non-nutritive sucking habits and facial morphology; no breast feeding or bottle feeding is reported.

Not selected - The study associates malocclusion to socioeconomic factors and to non-nutritive sucking habits; no breast feeding or bottle feeding is reported.

Not selected - Abstract

Not selected - The study does not associates malocclusion to bottle or breast feeding.

Not selected - The study does not associates malocclusion to bottle or breast feeding.

Not selected - The study describes the effect of myofunctional therapy on speech and disorders of articulation. 
58. Fabac E, Legouvic M, Zupan M. [The linkage between breast feeding and the growth of the orofacial area]. Fortschr Kieferorthop 1992; 53(4): 187-191.

59. Page DC. Breastfeeding is early functional jaw orthopedics (an introduction). Funct Orthod 2001; 18(3):24-27.

60. Baume LJ. The pattern of dental disease in French Polynesia. Int Dent J 1973; 23(4):579-584.

61. Larsson E. Artificial sucking habits: etiology, prevalence and effect on occlusion. Int J Orofacial Myology 1994; 20:10-21.

62. Verrastro AP, Stefani FM, Rodrigues CR, Wanderley MT. Occlusal and orofacial myofunctional evaluation in children with primary dentition, anterior open bite and pacifier sucking habit. Int J Orofacia Myology 2006; 32:7-21.

63. Garliner D. Facts that every mother should know when choosing an artificial nursing system for her child. Int J Orthod 1984; 22(4): 18-20.

64. Stecksen-Blicks C, Holm AK. Dental caries, tooth trauma, malocclusion, fluoride usage, toothbrushing and dietary habits in 4-year-old Swedish children: changes between 1967 and 1992. Int J Paediatr Dent 1995; 5(3): 143-148.

65. Karjalainen S, Ronning $\mathrm{O}$, Lapinleimu $\mathrm{H}$, Simell $\mathrm{O}$. Association between early weaning, non-nutritive sucking habits and occlusal anomalies in 3-year-old Finnish children. Int J Paediatr Dent 1999; 9(3): 169-173.

66. Peres KG, Oliveira Latorre MR, Sheiham A, Peres MA, Victora $C G$, Barros FC. Social and biological early life influences on the prevalence of open bite in Brazilian 6-year-olds. Int J Paediatr Dent $2007 ; 17(1): 41-49$.

67. Duncan K, McNamara C, Ireland AJ, Sandy JR. Sucking habits in childhood and the effects on the primary dentition: findings of the Avon Longitudinal Study of Pregnancy and Childhood. Int J Paediatr Dent 2008; 18(3): 178-188.

68. Sorensen HB, Artmann L, Larsen HJ, Kiaer I. Radiographic assessment of dental anomalies in patients with ectopic maxillary canines. Int J Paediatr Dent 2009; 19(2):108-114.

69. Heimer MV, Katz CR, Rosenblatt A. Anterior open bite: a casecontrol study. Int J Paediatr Dent 2010; 20(1):59-64.

70. Warren JJ, Bishara SE, Steinbock KL, Yonezu T, Nowak AJ. Effects of oral habits' duration on dental characteristics in the primary dentition. J Am Dent Assoc 2001; 132(12): 1685-1693.

71. Harrel SK. More about occlusion. J Am Dent Assoc 2005; 136(7):854, 856.

72. Davis DW, Bell PA. Infant feeding practices and occlusal outcomes: a longitudinal study. J Can Dent Assoc 1991; 57(7):593-594.

73. Chevitarese AB, Della VD, Moreira TC. Prevalence of malocclusion in 4-6 year old Brazilian children. J Clin Pediatr Dent 2002; 27(1):81-85.

74. Tsai HH, Sun KT. Growth changes of general and dental health status in Taiwanese children from mixed to early permanent dentition. J Clin Pediatr Dent 2004; 28(4):309-314.

75. Hebling SR, Cortellazzi KL, Tagliaferro EP, Hebling E, Ambrosano GM, Meneghim MC et al. Relationship between malocclusion and behavioral, demographic and socioeconomic variables: a cross-sectional study of 5 -year-olds. J Clin Pediatr Dent 2008; 33(1):75-79.

76. Charchut SW, Allred EN, Needleman HL. The effects of infant feeding patterns on the occlusion of the primary dentition. J Dent Child (Chic) 2003; 70(3): 197-203.
Not selected - the study is conducted with children under primary dentition

Not selected - Review

Not selected - The study reports frequency of oral problems in French Polynesian population; no risk factors are reported.

Not selected - Review

Not selected - The study associates malocclusion to orofacial myofunctional characteristics; breast feeding or bottle feeding are not reported.

Not selected - The study does not associates malocclusion to bottle or breast feeding.

Not selected - The study reports frequency of dental caries, dental trauma and malocclusion in Swedish children. There is no association with risk factors.

Not selected - Data could not be extracted for meta-analysis.

Not selected - the study is conducted with children under primary dentition

Not selected - The study does not report breast feeding or bottle feeding; only non-nutritive sucking habits.

Not selected - The study associates ectopic canines to their location in the maxilla; no malocclusion or risk factors are related.

Not selected - The study does not report breast feeding or bottle feeding; only non-nutritive sucking habits and growth pattern are reported.

Not selected - The study does not report breast feeding or bottle feeding; only non-nutritive sucking habits.

Not selected - Letters to the Editor

Not selected - the study is conducted with children under primary dentition

Not selected - The study does not associates malocclusion to bottle or breast feeding; only oral habits are reported.

Not selected - The study does not associates malocclusion to bottle or breast feeding.

Not selected - the study is conducted with children under primary dentition

Not selected - the study is conducted with children under primary dentition 
77. Caglar E, Larsson E, Andersson EM, Hauge MS, Ogaard B, Bishara $\mathrm{S}$ et al. Feeding, artificial sucking habits, and malocclusions in 3 -year-old girls in different regions of the world. J Dent Child (Chic) 2005; 72(1):25-30.

78. Nowak AJ. Feeding and dentofacial development. J Dent Res 1991; 70(2): 159-160.

79. Shendurnikar N. Thumb sucking: practitioners' guidelines. J Indian Med Assoc 1993; 91(1):24.

Not selected - The study reports prevalence data.

80. Alexander S, Hegde S, Sudha P. Prevalence of malocclusion and periodontal status in Tibetan school children of Kushalnagar, Mysore district. J Indian Soc Pedod Prev Dent 1997; 15(4):114-117.

81. Alexander LG. The thumb, the child, and the dentition or ignore the thumb, the tongue is worse. J Mass Dent Soc $1981 ; 30(3): 146,148-146,150$.

82. On B. Thilander \& B. Lennartsson: A study of children with unilateral posterior crossbite, treated and untreated, in the deciduous dentition. Occlusal and skeletal characteristics of significance in prediction the long-term outcome. (J Orofac Orthop 2002;63:371-85-3[No. 5].

83. Stahl F, Grabowski R. Orthodontic findings in the deciduous and early mixed dentition--inferences for a preventive strategy. J Orofac Orthop 2003; 64(6):401-416.

84. Grabowski R, Kundt G, Stahl F. Interrelation between occlusal findings and orofacial myofunctional status in primary and mixed dentition: Part III: Interrelation between malocclusions and orofacial dysfunctions. J Orofac Orthop 2007; 68(6):462-476.

85. Robke FJ. Effects of nursing bottle misuse on oral health. Prevalence of caries, tooth malalignments and malocclusions in North-German preschool children. J Orofac Orthop 2008; 69(1):5-19.

Not selected - Report

Not selected - Review

Not selected - The study reports malocclusion and periodontal status. No bottle or breast feeding are reported.

Not selected - The study does not associates malocclusion to bottle or breast feeding.

86. Neiva FC, Cattoni DM, Ramos JL, Issler H. [Early weaning: implications to oral motor development]. J Pediatr (Rio J) 2003; 79(1):7-12.

87. Carrascoza KC, Possobon RF, Tomita LM, Moraes AB. Consequences of bottle-feeding to the oral facial development of initially breastfed children. J Pediatr 2006; 82(5):395-397.

Not selected - Treatment study.

88. Starr NB, Poland C, III, Dean JA. Malocclusion: how important is that bite? J Pediatr Health Care 1999; 13(5):245-247.

Not selected - The study does not associate malocclusion to bottle or breast feeding.

Not selected - The study does not report breast feeding or bottle feeding.

Not selected - The stud correlates nursing bottle to its consequences such as nursing bottle caries and malocclusion. Types of malocclusion reported are crowding and premature loss of teeth and space in consequence to nursing bottle caries; not malocclusion caused by bottle feeding.

Not selected - Review

Not selected - Comparison group to bottle feeding was children that used glass (instead of bottle). Data of malocclusion are not described in the paper.

Not selected - The study does not report breast feeding or bottle feeding.

89. Massler M. Oral habits: development and management. J Pedod Not selected - The study does not associate malocclusion to breast 1983; 7(2): 109-119. feeding or bottle feeding.

90. Gimenez CMM, Moraes ABA, Ambrosano G, Castro FM. First childhood malocclusion's prevalence and its correlation with breast feeding and oral habits

19. Journal of Dental Research 2001; 80(4):1027.

91. Mendes ACR, Nobrega CBC, Pessoa CN, Souza ROA, Valenca AMG. Relation between breast-feeding types and duration, deleterious habits and malocclusions in children at joao pessoa city. Journal of Dental Research 2003; 82:238.

92. Masaracchia R. [Mother's breast or pacifier? Original or substitute?]. Kinderkrankenschwester 2009; 28(1 1):454-456.

93. Castellani G, Bertele GP, Zerman N. [Epidemiologic study in nursery schools of the Verona Commune on the occurrence of dental caries, malocclusion and bad habits that can influence the normal development of facial bone structure in children]. Minerva Stomatol 1987; 36(3):121-125.

94. Piras V, Tuveri F, Dessi C, Pittau R, Origa R, Basile R et al. [Relation between hypogonadism and malocclusion in betathalassemia major patients: analysis of 122 subjects]. Minerva Stomatol 2003; 52(5):241-246.

Not selected - Abstract

Not selected - Abstract

Not selected - Review

Not selected - The sudy does not report breast feeding or bottle feeding; only non nutritive sucking habits.

Not selected - The study is comprised of a selected group of patients with beta-thalassemia and its association with malocclusion. 
95. GEDICKE K. [On the predevelopment of the mandible in breast- and bottle-fed children from the standpoint of its function and the prevention of later distalization.]. Monatsschr Kinderheilkd $1961 ; 109: 361-369$.

96. Malagola C, Mandraffino AG, De Paolis M. [Role of feeding methods in the etiology of malocclusions]. Mondo Ortod 1986; 11 (5):39-44.

97. Gandini P, Schiavi A, Camassa D, Manuelli M. [Statistical survey of malocclusion in school age children]. Mondo Ortod 1989; 14(1):73-78.

98. Degano MP, Degano RA. Breastfeeding and oral health. A primer for the dental practitioner. N Y State Dent J 1993; 59(2):30-32.

99. Koev ZH. [Significance of breast feeding and bottle feeding in the development of the dentition]. Nauchni Tr Nauchnoizsled Stomatol Inst (Sofiia) 1969; 12:135-140.

100. Kuiipers-Jagtman AM. [Effects of sucking habits on the dentofacial development]. Ned Tijdschr Tandheelkd 1989; 96(6):256-258.

101. Salma S. Dentition and dental health. Nurs J India 2000; 91 (5): 102-104.

102. Early childhood pacifier use in relation to breastfeeding, SIDS, infection and dental malocclusion. Nurs Stand 2006; 20(38):52-55.

103. Djaha K, Adiko EF, Ly R, Egnankou KJ, Brou E, Vilasco J. [Harmful oral habits of African children]. Odontostomatol Trop 1986; 9(1):51-55.

104. Onyeaso CO. Need for preventive/interceptive orthodontic treatment among 7-10-year-old children in Ibadan, Nigeria: an epidemiological survey. Odontostomatol Trop 2004; 27(107):15-19.

105. Stirling DL. Conditions contributing to stability and instability of dental alignment. Ont Dent 1994; 71 (9):48-50.

106. Onyeaso CO, Isiekwe MC. Oral habits in the primary and mixed dentitions of some Nigerian children: a longitudinal study. Oral Health Prev Dent 2008; 6(3):185-190.

107. Raymond JL, Bacon W. [Influence of feeding method on maxillofacial development]. Orthod Fr 2006; 77(1):101-103.

108. Hashida S, Mihara J, Hashida K, Sumi N, Rakugi M, Ooshima T et al. [Clinical and statistical survey of the children at the Pedodontic Clinic of the Osaka University Dental Hospital]. Osaka Daigaku Shigaku Zasshi 1985; 30(2):336-344.

109. Lopez D, V, Singh GD, Feliciano N, Machuca MC. Associations between a history of breast feeding, malocclusion and parafunctional habits in Puerto Rican children. P R Health Sci J 2006; 25(1):31-34.

110. Adair SM, Milano M, Dushku JC. Evaluation of the effects of orthodontic pacifiers on the primary dentitions of 24- to 59-month-old children: preliminary study. Pediatr Dent 1992; 14(1):13-18.

111. Farsi NM, Salama FS. Sucking habits in Saudi children: prevalence, contributing factors and effects on the primary dentition. Pediatr Dent 1997; 19(1):28-33.

112. Watase S, Mourino AP, Tipton GA. An analysis of malocclusion in children with otitis media. Pediatr Dent 1998; 20(5):327-330.

113. Katz CR, Rosenblatt A. Nonnutritive sucking habits and anterior open bite in Brazilian children: a longitudinal study. Pediatr Dent 2005; 27(5):369-373.

114. Warren JJ, Slayton RL, Bishara SE, Levy SM, Yonezu T, Kanellis MJ. Effects of nonnutritive sucking habits on occlusal characteristics in the mixed dentition. Pediatr Dent 2005; 27(6):445-450.

115. Costantino A. [Class II malocclusion and bottle feeding]. Prev Assist Dent 1986; 12(2): 19-22.
Not selected - The study does not associate malocclusion to breast feeding or bottle feeding.

Not selected - The study does not associate malocclusion to breast feeding or bottle feeding.

Not selected - The study describes only frequency data.

Not selected - Review

Not selected - Review

Not selected - Review

Not selected - Review

Not selected - Review

Not selected - The study does not associate malocclusion to breast feeding or bottle feeding.

Not selected - The study does not associate malocclusion to breast feeding or bottle feeding.

Not selected - Review

Not selected - The study does not report breast feeding or bottle feeding; only non-nutritive sucking habits.

Not selected - Review

Not selected - The study does not associate malocclusion to breast feeding or bottle feeding.

Not selected - the study is conducted with children under primary dentition

Not selected - The study correlates malocclusion with the use of orthodontic pacifiers. No feeding habits are reported.

Not selected - The study does not correlate breast feeding or bottle feeding to malocclusion; it is related only to non-nutritive sucking habits.

Not selected - The study is comprised of a high selected group of patients with otitis media. Other variables are associated to otitis media, but not malocclusion and feeding habits directly.

Not selected - The study does not report breast feeding or bottle feeding; only non-nutritive sucking habits.

Not selected - The study does not report breast feeding or bottle feeding; only non-nutritive sucking habits.

Not selected - The study has no statistical data. 
116. Bertoldi PM, Felficio CM, Matsumoto MA. [Effect of the early intervention of oral habits on the development of dental occlusion]. Pro Fono 2005; 17(1):37-44.

117. Maciel CT, Leite IC. [Etiological aspects of anterior open bite and its implications to the oral functions]. Pro Fono 2005; 17(3):293-302.

1 18. Myllarniemi S. Oral and dental state in Helsinki preschool children. V. Oral habits and occlusion. Proc Finn Dent Soc 1973; 69(4):157-163.

119. Helle A, Haavikko K. Prevalence of earlier sucking habits revealed by anamnestic data and their consequences for occlusion at the age of eleven. Proc Finn Dent Soc 1974; 70(5):191-196.

120. Nystrom M. Occlusal changes in the deciduous dentition of a series of Finnish children. Proc Finn Dent Soc 1981; 77(5):288-295.

121. Usadel W. Duration of nursing and condition of bite. An evaluation of 1000 histories of patients from an orthodontics practice. Quintessence Int (Berl) 1970; 1 (7):61-62.

122. Usadel W. [Breast feeding time and bite position. An analysis of 1000 anamneses of patients in an orthodontic practice]. Quintessenz 1967; 18(2):95-96.

123. Luft R. [Preventive measures for the prevention of malocclusion in infants]. Quintessenz 1977; 28(4):81-88.

124. Peters $S$. [Influence of early nursing on jaw and facial growth]. Quintessenz J 1988; 18(9):865-869.

125. Kimmel K. [“With growth” nipple size--important aid to jaw development]. Quintessenz J 1990; 20(11):1013-1017.

126. Calo FA. [Physiology and pathology resulting from sucking]. Rev Circ Argent Odontol 1968; 31 (1):23-26.

127. Lescano dF, Varela d, V. [Effect of the suction-swallowing action on orofacial development and growth]. Rev Fac Cien Med Univ Nac Cordoba 2006; 63(2 Suppl):33-37.

128. Gudin RG, Khalef M. [Abnormalities in behavior in the oral and cervical area: reassurance breast-feeding. Considerations on sudden infant death]. Rev Laryngol Otol Rhinol 1993; 114(4):297-303.

129. Leite-Cavalcanti A, Medeiros-Bezerra PK, Moura C. [Breastfeeding, bottle-feeding, sucking habits and malocclusion in Brazilian preschool children]. Rev Salud Publica (Bogota) 2007; 9(2): 194-204.

130. Tomita NE, Bijella VT, Franco LJ. [The relationship between oral habits and malocclusion in preschool children]. Rev Saude Publica 2000; 34(3):299-303.

131. Peres KG, Barros AJ, Peres MA, Victora CG. Effects of breastfeeding and sucking habits on malocclusion in a birth cohort study. Rev Saude Publica 2007; 41 (3):343-350.

132. Tollaro I, Casini RG. [Bad sucking habits and their repercussions on the structure of the face, mouth and jaws]. Riv Clin Pediatr 1968; 81(6):1117-1124.

133. Maggioni A. [Bad habits that cause oral malocclusions]. Riv Odontostomatol Implantoprotesi 1984;(8):104-106.

134. Linder A, Modeer T. Relation between sucking habits and dental characteristics in preschoolchildren with unilateral cross-bite. Scand J Dent Res 1989; 97(3):278-283.

135. Ito $G$. [Skeletal and discrepancy factors in malocclusion]. Shikai Tenbo 1984; 63(7): 1463-1470.

136. Oikawa K. [Malocclusion in maternal and child health]. Shikai Tenbo 1984; 63(7):1431-1440.
Not selected - The study reports the effect of counseling on interruption of oral habits.

Not selected - The study does not associates feeding habits to malocclusion.

Not selected - The study does not report breast feeding or bottle feeding; only non-nutritive sucking habits

Not selected - The study does not report breast feeding or bottle feeding; only non-nutritive sucking habits

Not selected - The study reports changes of malocclusion during years; no risk factors are reported.

Not selected - The study does not have sufficient quantitative data for data's extraction.

Not selected - The study is comprised of a selected group of patients from clinical practice.

Not selected - The study does not associate malocclusion to breast feeding or bottle feeding.

Not selected - Review

Not selected - The study does not associate malocclusion to breast feeding or bottle feeding.

Not selected - Review

Not selected - the study is conducted with children under primary dentition

Not selected - Review

Not selected - the study is conducted with children under primary dentition

Not selected - The study does not report breast feeding or bottle feeding; only non-nutritive sucking habits.

Selected - The study is part of Pelota's cohort study. Did not enter meta-analysis.

Not selected- The study reports sucking habits.

Not selected - Review

Not selected - The study does not report breast feeding or bottle feeding; only non-nutritive sucking habits.

Not selected - The study describes skeletal traits.

Not selected - Review 
137. Takanashi N, Naya K, Masumori M, Nakano J, Ohama A, Hirata J et al. [Survey on nutrition of infants in the Tokyo metropolitan area. 1. Carious dentitions, anomalies of occlusion and ways of eating]. Shoni Shikagaku Zasshi 1989; 27(3):708-715.

138. Callaghan A, Kendall G, Lock C, Mahony A, Payne J, Verrier L. Association between pacifier use and breast-feeding, sudden infant death syndrome, infection and dental malocclusion (Provisional abstract). SO: International Journal of Evidence-Based Healthcare 2005; 3(6): 147-167.

139. Rakosi T. [Prevention of malocclusions and preventive orthodontics]. SSO Schweiz Monatsschr Zahnheilkd 1969; 79(10):1169-1188.

140. Taatz H. [Orthodontic prophylaxis]. Stomatol DDR 1978; 28(5):342-351.

141. Obraztsov I. [A clinico-statistical analysis of the risk factors for the occurrence of maxillodental anomalies in children]. Stomatologiia (Mosk) 1991; 70(1):66-69.

Not selected - The study reports prevalence data.

142. Larsson E, Jarvheden B. Dummy- and finger-sucking habits with special attention to their significance for facial growth and occlusion. 2. Background variables. Sven Tandlak Tidskr 1971; 64(1 1):781-788.

143. Larsson E. Dummy- and finger-sucking habits with special attention to their significance for facial growth and occlusion. 1 . Incidence study. Sven Tandlak Tidskr 1971; 64(10):667-672.

144. Larsson E. Dummy- and finger-sucking habits with special attention to their significance for facial growth and occlusion. 3 . Weaning. Sven Tandlak Tidskr 1972; 65(1):1-5.

145. Larsson E. Dummy- and finger-sucking habits in 4-year-olds. Sven Tandlak Tidskr 1975; 68(6):219-224.

146. Larsson E. Effect of dummy-sucking on the prevalence of posterior cross-bite in the permanent dentition. Swed Dent J 1986; 10(3):97-101.

147. Ahlgren J. EMG studies of lip and cheek activity in sucking habits. Swed Dent J 1995; 19(3):95-101.

148. Westling L, Mohlin B. Palatal dimensions and some inherited factors (body height and metacarpal index). Swed Dent J 1996; 20(4):141-149.

149. Larsson E. Orthodontic aspects on feeding of young children. 1. A comparison between Swedish and Norwegian-Sami children. Swed Dent J 1998; 22(3):117-121.

150. Schneider HG, Hierse P, Hierse H, Deichsel E. [Effect of the parental home on the oral health status of children]. Z Gesamte Hyg 1989; 35(9):523-526.

151. Rakosi T. [Significance of early infancy in the development of malocclusion]. Zahnarztl Prax 1972; 23(12):321-322.

Not selected - Pacifier use is the main outcome.

Not selected - The study reports prevention methods.

Not selected - Review

Not selected - The study does not associate malocclusion to breast feeding or bottle feeding.

Not selected - Non-nutritive sucking habits is the main outcome.

Not selected - Non-nutritive sucking habits is the main outcome.

Not selected - Non-nutritive sucking habits is the main outcome.

Not selected - Non-nutritive sucking habits is the main outcome.

Not selected - The study does not report breast feeding or bottle feeding; only non-nutritive sucking habits.

Not selected - The study evaluated lip and cheek activity; no risk factors or malocclusion were evaluated.

Not selected - The study does not report breast feeding or bottle feeding.

152. Milicic A. [Prevention of orthodontic anomalies in infants]. Zobozdrav Vestn 1972; 27(1):41-44.

Not selected - The study does not evaluate malocclusion; only feeding practices.

Not selected - The study does not report malocclusion as main outcome.

Not selected - Review

153. Paunio P, Rautava P, Sillanpaa M. The Finnish Family Competence Study: the effects of living conditions on sucking habits in 3 -year-old Finnish children and the association between these habits and dental occlusion. Acta Odontol Scand 1993; $51(1): 23-29$.

154. Kimmel K. [What became of them? I. A bottle nipple and a jawshaper, 25 years after their invention]. ZWR 1980; 89(2):62-67.

155. Melink S, Vagner MV, Hocevar-Boltezar I, Ovsenik M. Posterior crossbite in the deciduous dentition period, its relation with sucking habits, irregular orofacial functions, and otolaryngological findings. 1 Am J Orthod Dentofacial Orthopedics 138, 32-40. 2010.

Not selected - The study reports prevention and orthodontics.

Not selected - Non-nutritive sucking habits is the main outcome.

Not selected - Review

Not selected - the study is conducted with children under primary dentition 
156. Mendes ACR, Valença AMG, Lima CCMd. [Association between breast-feed, non-nutritive habits and malocclusions among children between 3 and 5 years old]. Ciencia Odontologica Brasileira 11 [1], 67-75. 2008.

157. Dolci GS, Ferreira EJB, Mello ALSF. [Relations between sucking habits and malocclusions]. J Bras Odonton Ortop Facial 6[35], 379-385. 2001.

158. Almeida SPTdMA, Paixão RdF, Vieira GO. [Influence of milkfeeding type, suction and malocclusion habits: systemic review of literature]. J Bras Odonton Ortop Facial 10[57], 275-289. 2005.

159. Boni RC, Veiga MCFdA, Almeida RCd. [Comportment of anterior open bite, after, the retreat the habit of sucking]. J Bras Orthod Ortop Maxilar 2[12], 35-40. 11997.

160. Mahalski PA, Stanton WR. The relationship between digit sucking and behaviour problems: a longitudinal study over 10 years. J Child Psychol Psychiatry 33[5], 913-923. 1992.

161. Shetty SR, Munshi AK. Oral habits in children-a prevalence study. J Indian Soc.Pedod.Prev.Dent. 61-66. 1998.

162. Zuanon ACC, Oliveira MdF, Giro EMA, Maia JP. [Relationship between oral habits and malocclusion in the primary teeth]. JBP - Rev iberoamericana odontop odontol bebe 3[12], 104-108. 2000.

163. Thomazine GDPA, Imparato JCP. [Prevalence of open bite and cross bite in the students of public schools of Campinas]. JBP - Rev iberoamericana odontop odontol bebe 3[1 1], 29-37. 2000.

164. Ferreira SH, Ruschel HC, De Bacco G, Ulian J. [Prevalence of anterior open bite in 0-5 year-old children attended at day nurseries in Bento Gonçalves - RS]. JBP - Rev iberoamericana odontop odontol bebe 4[17], 74-79. 2001.

165. Gallarreta FWdM, Silva AMTd, Toniolo IMF. [Duration of breastfeeding and use of the bottle related to pacifier sucking habit and dental occlusion]. JBP - Rev iberoamericana odontop odontol bebe 7[40], 552-448. 2004.

166. Borghoff MJ, Mombelli ML, Murakami RM, Goldenberg FC, Bommarito S. [Breast feeding and the relationship with oral habits and malocclusions on mixture denture]. Odonto (São Bernardo do Campo) 13[26], 95-104. 2005.

167. Onyeaso CO, Isiekwe MC. Oral habits in the primary and mixed dentitions of some Nigerian children: a longitudinal study. 3. Oral Health Prev.Dent. 6, 185-190. 2008.

168. Kobayashi HM, Scavone Junior H, Ferreira RI, Garib

DG. [Relanshionshipbetween non-nutritive sucking habits and posterior crossbite in the deciduous dentition]. Ortodontia $41[4], 367-372.2008$.

169. Aravena A. P, Alvarez J. F, Roizen G. S. [Effect of bad sucking habit in the dentition of children]. Pediatr día 14[5], 269-272. 1998.

170. Sousa JM, Fracasso MLC. [Maternal behavior versus child temper: influence on the oral health pattern]. Comportamento materno versus temperamento da criança: influência no padrão de saúde bucal. Pesquisa brasileira em odontopediatria e Clínica Integrada 10[1]. 2010. :47-54

171. Moraes ESd, Lira CC, Ely MR, Thomaz EBAF, Valença AMG. [Prevalence of openbite and crossbite in deciduous dentition ]. Rev Bras Ciênc Saúde 5[1], 23-30. 2001.

172. Silva LPMd, Souza Júnior MA, Bastos EPdS. [Posterior crossbite in deciduous dentintion. Relationship with oral habits]. Rev Bras Odontologia 62[1/2], 49-51. 2005.
Not selected - The study does not report outcome of breast feeding. Breast feeding is only associated to non-nutritive sucking habits.

Not selected - The study does not report breast feeding or bottle feeding; only associated non-nutritive sucking habits.

Not selected - Review

Not selected - The study reports the effects of counseling on malocclusion.

Not selected - The study is about digit sucking habits associated to behavior problems; no breast feeding or bottle feeding is reported.

Not selected - Is a prevalence study.

Not selected - The study reports oral habits.

Not selected - the study describes prevalence data of open bite; breast feeding or bottle feeding were not evaluated.

Not selected - the study describes prevalence data of open bite; breast feeding or bottle feeding were not evaluated.

Not selected - The study associates breast feeding to sucking habits.

Not selected - only patients with malocclusion are described, patients without malocclusion are not described. Sample from a orthodontic clinic (university).

Not selected - The study reports non-nutritive sucking habits and malocclusion.

Not selected - The study reports sucking habits and malocclusion.

Not selected - The study is a review.

Not selected - The study does not associates breast feeding or bottle feeding to malloclusion; only prevalence data is reported.

Not selected - The study does not report breast feeding or bottle feeding; only associated non-nutritive sucking habits.

Not selected - the study is conducted with children under primary dentition 
173. Oliveira ABd, Souza FPd, Chiappetta ALdML. [The relationship between non-nutritive sucking habits, infant feeding methods and malocclusion in children with primary dentition]. Rev CEFAC 8[3], 352-359. 2006.

174. Fote FD, Bosco VL. [Prevalence of habits of non nutritive suction in Florianópolis-SC's children]. Rev Fac Odontol Univ Fed Bahia 20, 25-28. 2000.

175. Tomita LM, Carrascoza KC, Possobon RdF, Ambrosano GMB, Moraes ABAd. [The relathionship between breastfeeding duration, oral habits introduction and malocclusion ocurrence]. Rev Fac Odontologia da Univ Passo Fundo 9(2), 101-104. 2004.

176. Martins RJ, Forte FDS, Garbin CAS, Saliba NA. [Ralationship between non-nutritive sucking habits and anterior open bite]. Rev Inst Ciên Saúde 21 [4], 401-404. 2003.

177. Thomaz EBAF, Valença AMG. [Prevalence of malocclusions and factors related to its occurence in preschool children in São Luís - MA - Brazil]. Rev Pós-Graduação 12[2], 212-221. 2005.

178. Furtado ANdM, Vedovello Filho M. [The outcomes of the breast-feeding period in the settlement of nonnutritive sucking habits and in the occurrence of malocclusion in primary dentition]. RGO 55[4], 337-341. 2007.

179. Dimberg L, Bondemark L, Soderfeldt B, Lennartsson B. Prevalence of malocclusion traits and sucking habits among 3-yearold children. Swed.Dent.J 34[1], 35-42. 2010.

180. Souza Júnior MA. [Contribution to the study of the posterior cross-bite effect in complete primary dentition]. Contribuiçäo ao estudo da mordida cruzada posterior em dentiçäo decídua completa. THESIS/ RIO DE JANEIRO . 1998.

181. Soviero VLM. [Study of the influence of feeding methods and durantion in the no nutrition sucking habits development and dental oclusion in the primary dentition]. Estudo da influência do tipo e duraçäo do aleitamento no desenvolvimento de hábitos de sucçäo näo nutritivos e no relacionamento entre as arcadas decíduas. THESIS/ RIO DE JANEIRO. 1999.

182. Verrastro AP. [Association between nutritive and non nutritive sucking habits and occlusal and oral myofunctional characteristics in children with primary dentition]. Associação entre os hábitos de sucção nutritiva e não nutritiva e as características oclusais e miofuncionais orais em crianças com dentição decídua. THESIS/MONOGRAPH, 150p. 2008.

183. Castro LAd. [Cross-section study of the evolution of primary dentition]. Estudo transversal da evoluçäo da dentiçäo decídua. THESIS/RIO DE JANEIRO. 2001.

184. Ribeiro-Jr, H. [Influence of nutritive and non-nutritive sucking habits on primary occlusion of brazilian children: a case-control study]. Influence of nutritive and non-nutritive sucking habits on primary occlusion of brazilian children: a case-control study. THESIS.

185. Katz CRT. [Relationship among nonnutritive sucking habits, anterior open bite, posterior crossbite and facial morphology in children preschool in the city of Recife/PE, Brazil: a longitudinal study]. Relação entre hábitos de sucção, mordida aberta anterior, mordida cruzada posterior e morfologia facial em pré-escolares do Recife/PE: um estudo longitudinal. THESIS. 2003.

186. Gimenez CMM, Moraes ABA, Bertoz AP, Bertoz FA, Ambrosano GB. Prevalência de más oclusões na primeira infância e sua relação com as formas de aleitamento e hábitos infantis, R Dental Press Ortodon Ortop Facial 13[2]:70-83, 2008.
Not selected - the study is conducted with children under primary dentition

Not selected - The study does not report outcomes of malocclusion, breast feeding or bottle feeding.

Not selected - The study does not associate feeding habits and malocclusion.

Not selected - The study does not report breast feeding or bottle feeding; only associated non-nutritive sucking habits.

Not selected - The study does not report breast feeding or bottle feeding as risk factors.

Not selected - the study is conducted with children under primary dentition

Not selected - The study does not report breast feeding or bottle feeding; the study evaluated non-nutritive sucking habits, breathing pattern and snoring.

Not selected - The published study was identified and selected. The thesis was excluded in order to avoid duplicate data.

No

Not found

Not found

(20)

Not selected

Not selected -The study evaluates the primary dentition and its development.

Not selected

Not selected - The study is a thesis and it was published in scientific periodicals. Papers published were not read and not selected. The study is about non-nutritive sucking habits.

Not selected - The study describes p-value of the statistics between malocclusion and feeding habits, but it was not possible to extract data. 
187. Jabbar NS, Bueno AB, Silva PE, Scavone-Junior $H$, Ines FR. Bottle feeding, increased overjet and Class 2 primary canine relationship: is there any association? Braz Oral Res 2011 Jul;25(4):331-7.

188. Romero CC, Scavone-Junior H, Garib DG, Cotrim-Ferreira FA, Ferreira RI. Breastfeeding and non-nutritive sucking patterns related to the prevalence of anterior open bite in primary dentition. J Appl Oral Sci 2011 Apr;19(2):161-8.

189. Vasconcelos FM, Massoni AC, Heimer MV, Ferreira AM, Katz CR, Rosenblatt A. Non-nutritive sucking habits, anterior open bite and associated factors in Brazilian children aged 30-59 months. Braz Dent J 2011 ;22(2): 140-5.

190. Diouf JS, Ngom PI, Badiane A, Cisse B, Ndoye C, Diop-Ba K, et al. Influence of the mode of nutritive and non-nutritive sucking on the dimensions of primary dental arches. Int Orthod 2010 Dec;8(4):372-85.

191. Montaldo L, Montaldo P, Cuccaro P, Caramico N, Minervini G. Effects of feeding on non-nutritive sucking habits and implications on occlusion in mixed dentition. Int J Paediatr Dent 201 1; 21:68-73.

192. Castelo PM, Gaviao MB, Pereira LJ, Bonjardim LR. Maximal bite force, facial morphology and sucking habits in young children with functional posterior crossbite. J Appl Oral Sci 2010 Mar; 18(2): 143-8.

193. Gimenez CMM, Moraes ABA, Bertoz AD, Bertoz FA, Ambrosano GB. Prevalence of maloccclusion in primary dentition and relation with feeding habits. R Dental Press Ortodon Ortop Facial 2008; 13:70-83. Manual search

194. Narbutyte I, Narbutyte A, Linkeviciene L. Relationship between breastfeeding, bottle-feeding and development of malocclusion. Stomatologija 2013;15:67-72.

195. Thomaz EB, Cangussu MC, Assis AM. Malocclusion and deleterious oral habits among adolescents in a developing area in northeastern Brazil. Braz Oral Res. 2013;27:62-69.

196. Caramez da SF, Justo Giugliani ER, Capsi PS. Duration of breastfeeding and distoclusion in the deciduous dentition. Breastfeed Med. 2012;7:464-468.
Not selected - the study is conducted with children under primary dentition

Not selected - the study is conducted with children under primary dentition

Not selected - the study is conducted with children under primary dentition

Not selected

No selected - The study only associates feeding habits to non-nutritive sucking habits.

Not selected - the study is conducted with children under primary dentition

Selected - The study includes children with special needs what can be a confounder, since this population are more prompt to malocclusions. Not possible data extraction.

Not selected - Review

Not selected - The study does not report breast feeding or bottle feeding; only associated non-nutritive sucking habits

Not selected - the study is conducted with children under primary dentition 